\title{
Additions to the NASDAQ National Market System: An Analysis of Stock Returns and Trading Volume
}

Dr. Daniel P. Klein, Finance, Bowling Green State University

Dr. Glenn Wolfe, Finance, University of Toledo

Dr. Linda E. Bowyer, Finance, University of Toledo

\begin{abstract}
In this study, empirical tests are conducted to determine the effect on stock returns and volume of addition to the NASDAQ National Market System (NMS). By analyzing stock returns and trading volume, the results support a positive effect for stocks added to the NMS. However, the addition appears to be a more positive event for low market value stocks relative to high market value stocks.
\end{abstract}

\section{Introduction}

The introduction of the National Association of Securities Dealers Automatic Quotation (NASDAQ) system in the Over-the-Counter (OTC) market in 1971 was done with the intent of increasing the communication and flow of information for OTC stocks among dealers making up the market in the various issues. Subsequent to the introduction of NASDAQ, the NASDAQ National Market System (NMS) was instituted on April 1, 1982 to help promote major OTC stocks in a quasi-exchange environment.

The purpose of this paper is to examine the effect on stock returns and volume associated with the movement of OTC stocks from NASDAQ/OTC to NASDAQ/ NMS.(1) The research is important for several reasons. First, no previous research has studied the issue of the effects of inclusion on stocks being placed on the NMS. Consequently, results will add to the body of knowledge that exists with regard to the listing effect on securities. Second, previous work in the area of listing has studied movement of stocks from the OTC market to a listed exchange (NYSE or ASE). It is possible that results from these works may be confounded by institutional effects (e.g., price reporting differences) as well as the listing process itself (application, review process, etc.). The work proposed here represents the impact of a pure "listing" effect since 1) the stocks do not move out of the OTC environment and 2) the process for being placed on the NMS is much shorter, and the event date more easily identified for methodological purposes, than the process for being listed on the NYSE or ASE. Third, the study considers the influence of the firm size effect on the returns of the stocks being added to the NMS. The size effect is a well documented phenomenon (for example, see Roll (1981) and Keim (1987)). Specifically, the listing on NMS may have more informational value for smaller, less well-known companies than for larger companies. No previous listing study has considered this factor. Finally, from an institutional point of view, the research addresses the issue of whether or not companies derive any measurable benefits from being included on NASDAQ/NMS. The research is timely from this point of view in that the NASD is considering making the requirements for inclusion on the NMS more stringent than those currently being applied. The proposed rule changes are addressed in File No. SR-NASD-90-8 of the SEC.

\section{Literature Review}

Previous research in the area of listing stocks on organized exchanges has, for the most part, centered attention on two aspects: 1) the listing effect on stock returns and 2) potential changes in a stock's risk level due to listing. Listing has been hypothesized to be a positive event for a company's stock for generally two reasons: 1) the idea that the company has "arrived" due to its ability to meet listing requirements, and, subsequently, potentially more information flow on the company; and, 2) potential improvements in the liquidity of trading in a stock on an exchange relative to the OTC. Early studies by Van Horne (1970) and Furst (1979) did not provide support for a positive impact of listing. However, Ying, Lewellen, Schlarbaum, and Lease (YLSL) (1977) found that, on a risk-adjusted basis, excess returns were significantly positive for the time leading up to listing. Although excess returns were moderately, significantly negative in the 24 months 
post-listing, stocks gave up only about $50 \%$ of the pre-listing cumulative excess returns. Fabozzi's (1981) results did not support YLSL as he found that, although excess returns were positive in the pre-listing to listing time frame, stocks gave up these excess returns, and more, in the post-listing period.

Perhaps of most interest is that these studies, in particular YLSL and Fabozzi, found a pre-listing positive effect and a post-listing negative effect. More recent work by McConnell and Sanger $(1975,1986,1987)$ has supported these anomalies. Grammatikos and Papaioannou (GP) (November 1986) found that listing has a larger effect on companies that stand to gain greatly from listing (i.e., "low performers" as based on a poor earnings record in the time leading up to listing). In another study, GP (Fall 1986) found that stocks with relatively high liquidity (as measured by average spread) in the OTC market stand to gain little (as measured by changes in stock returns) by being listed on an exchange.

The measurement of excess returns, and, consequently, the results of previous research, may be affected by shifting parameters, in particular the measurement of Beta for risk-adjusted models. If listing increases information flow, systematic risk may be lowered; and, the use of a pre-listing risk measurement for post-listing returns may artificially lower the measurement of excess returns in the post-listing period. Dhaliwal (1983) contends that increased information for newly listed stocks may reduce risk and equity cost of capital. Reints and Vandenburg (1975) found that Beta levels for stocks changing location did not change. However, Bhandari, et al. (1989) found that, in the early post-listing period, risk not only shifted, it increased. Risk appeared to decrease over time, however, through a seasoning process.

The results from previous research may be confounded to a significant degree by institutional differences across the markets (OTC vs. exchange). Therefore, it is difficult to tell if the results are due strictly to the event of being listed. The fact that stocks do not change institutions in this study may provide some light on the issue of whether or not stocks, and therefore companies, benefit from being included on a national stock system.

\section{Background}

According to officers of NASD, companies potentially derive benefits from having their stocks included on the NMS, as opposed to being on NASDAQ/OTC, for three reasons. First, trading volume is reported immediately upon the trade being made and prices are updated immediately -- i.e., real-time transaction reporting. This is intended to increase information availability and enhance stock liquidity as compared to NASDAQ/OTC stocks since information on these stocks (specifically, volume) is updated only with significant time lags (at the end of the trading day). Second, more newspapers print the trading activity of NMS listings as compared to complete OTC listings. Third, there may be some intangible prestige similar to being on a listed exchange. Taken together, these three reasons potentially make NMS stocks more attractive than an OTC listing; and, may make the move to an exchange unnecessary.(2) In many cases, the move to an organized exchange may not be possible due to the inability of the company to meet the listing requirements. Thus, the placement on the NMS provides a benefit that would not otherwise be available. Additionally, the cost of "moving" from the OTC to the NMS is borne by the NASD. Consequently, there is no external cost imposed on firms to be included in the NMS as there is for firms to have their stocks listed on an organized exchange.

The process for inclusion on the NMS is relatively straightforward. In order to be included on the NMS, the company and its stock must meet certain requirements.(3) Requirements, historically, have been established by NASD for both voluntary and mandatory inclusion in the NMS.(4) Once the requirements have been met, the stocks are added to the NMS on the first or third Tuesday of the month. The NASD notifies the company ten calendar days (approximately seven trading days) prior to the actual listing on the NMS.(5) The company can publicize the coming event, if it so chooses. Approximately two days before inclusion on the NMS the NASD notifies the Wall Street Journal (WSJ) so that the editors of the WSJ can change the typesetting for stock quotations. The NASD does not publish a press release regarding the change in the stock's trading location.

\section{Methodology and Results}

The benefits to be derived from moving to the NMS from the OTC, as stated above, suggest that two measures may be impacted. In particular, stock returns and stock volume may be affected by such a change in trading location. That is, if the move to the NMS does increase information flows on a company's stock, and, consequently, increases interest on the part of individuals and institutions for holding the stock, then both returns and volume might be expected to show relative increases around the event day.

\section{A. Analysis of Excess Returns}

The time frame for the study is from the inception of the NMS on April 1, 1982 through June, 1987.(6) Daily returns are obtained from the NASDAQ CRSP tape. These returns are analyzed using the market model in standard event methodology.(7) Briefly, daily returns are assumed to be generated by the model

$R(j t)=a+b(j) R(m t)+e(j t)$ 
where $R(j t)$ is the daily return for stock $j$ on day $t, R(m t)$ is the daily return associated with the market portfolio, and $b(j)$ is the Beta coefficient for stock $j$. The market index employed here is the value-weighted OTC Composite Index. Ex post excess returns are generated by

$$
X R(j t)=R(j t)-(\hat{a}+\hat{b}(j) R(m t))
$$

where $\mathrm{XR}(\mathrm{jt})$ represents the excess returns for stock $\mathrm{j}$ on day $t$, relative to the market model. Parameters for the market model are estimated over the period from day $t=$ -310 to day $t=-61$ in order to calculate excess returns from day $t=-60$ to day $t=+60$. These excess returns are averaged across the $\mathrm{N}$ securities in the sample for each day $t$ to arrive at an average excess return for day $t, \operatorname{AXR}(t)$. In addition, cumulative average excess returns from time $t=a$ to time $t=b, \operatorname{CAXR}(a b)$, are computed to study the trend in daily average excess returns. T-tests are performed on both daily average excess returns and on CAXR(ab) to test the significance of both measures. The appendix details the methods used to calculate the $\operatorname{AXR}(t), \operatorname{CAXR}(a b)$, and the t-tests.

Using the NASDAQ CRSP tape, 1782 stocks were positively identified as being added to NMS. Of these, 1746 met the requirement of 310 trading days prior to and 60 days after the event day. The event day itself can be defined in two ways. The first definition of time $t=$ 0 is the addition day itself; that is, the day the stock begins trading on NMS. The second definition of $t=0$ takes into account the fact that the company is notified approximately seven trading days prior to addition and can publicize the coming event. Thus, due to potential leaking of information, the excess returns will be scrutinized around day $t=-7$ (relative to the addition day) for any abnormal behavior.

Table 1 shows the results of inclusion on the NMS for the full sample of 1746 stocks. There are no days from day $t=-7$ to day $t=-1$ for which average excess returns are significantly different from zero, positive or otherwise. However, a significant positive excess return, at only the 0.10 level of significance, occurs at day $t=$ -8 (or at the extreme time frame for company notification) indicating a possible leak in information regarding the change in trading location. This result, given its level of significance, may also be spurious. Consequently, there does not appear to be strong indication of information leakage prior to a stock's inclusion on NMS. Day $\mathrm{t}=0$ results in a positive average excess return of $0.12 \%$ with a significance level value of 0.077 while day $\mathrm{t}=+1$ results in a positive average excess return of $0.16 \%$ with a significance level of 0.015 .(8) The CAXR for the five trading days beginning with day $t=0$ (i.e., the initial week of inclusion on the NMS) is 0.0030 , or a $0.3 \%$ positive return. It is difficult to compare the results as presented here with the results of other studies due to different time frames as well as different method- ologies and event periods (weekly, monthly, etc.). Nevertheless, the general result of positive excess returns at the time of inclusion is in accord with the results of other studies. Consequently, one can view the move from the OTC to the NMS as a positive event for a company's stock.

Additionally, as seen in Chart 1 and as occurs with other studies, the CAXR increases up to and slightly after inclusion (until day $t=+13$ ), but decreases after that and, in fact, loses most of the gains by day $t=+30$ that had accumulated over the previous four months' time. Both results (increasing to and slightly beyond inclusion and decreasing thereafter) agree with the general results of previous studies that dealt with movement of stocks from the OTC to an organized exchange. This phenomenon of rising CAXRs up to inclusion and falling afterward, may be due, in part to the information effects associated with firm size. The size effect is considered later in this paper.

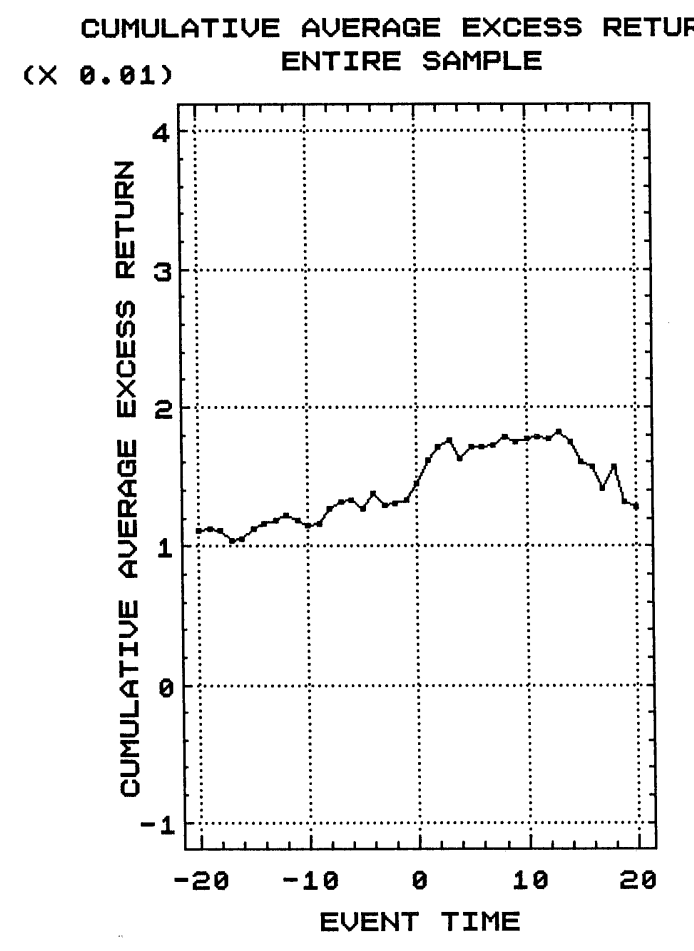

\section{B. Discussion of Items Impacting Excess Returns}

The results presented here may be influenced by statistical as well as institutional factors. In particular, three factors that could potentially influence excess returns are discussed. These factors are: 1) a shift in the estimate of beta; 2) NASD requirement changes for inclusion on NMS; and, 3) the size of the company (as measured by the market value of the common stock).

\section{i. Shift in Beta Estimates.}

Instability of the parameter used to calculate excess 
TABLE 1

Excess Returns for the Entire Sample

\begin{tabular}{|c|c|c|c|}
\hline Event Day & $\underline{\text { Average Excess }}$ Returns $^{a}$ & t-statistic & $\underline{\mathrm{CAXR}}^{\mathrm{a}}$ \\
\hline-60 & 0.0023 & 0.3471 & 0.0023 \\
\hline-50 & -0.0005 & -0.0784 & 0.0028 \\
\hline-40 & 0.0068 & 1.0158 & 0.0514 \\
\hline-30 & -0.0009 & -0.1372 & 0.0849 \\
\hline-20 & -0.0010 & -0.1516 & 0.1106 \\
\hline-15 & 0.0076 & 1.1316 & 0.1126 \\
\hline-14 & 0.0031 & 0.4602 & 0.1157 \\
\hline-13 & 0.0020 & 0.2930 & 0.1177 \\
\hline-12 & 0.0043 & 0.6490 & 0.1220 \\
\hline-11 & -0.0043 & -0.6354 & 0.1177 \\
\hline-10 & -0.0034 & -0.5036 & 0.1144 \\
\hline-9 & 0.0009 & 0.1311 & 0.1153 \\
\hline-8 & 0.0113 & $1.6854 *$ & 0.1266 \\
\hline-7 & 0.0055 & 0.8158 & 0.1320 \\
\hline-6 & 0.0003 & 0.0506 & 0.1324 \\
\hline-5 & -0.0055 & -0.8267 & 0.1268 \\
\hline-4 & 0.0109 & 1.6296 & 0.1377 \\
\hline-3 & -0.0083 & -1.2360 & 0.1295 \\
\hline-2 & 0.0004 & 0.0525 & 0.1298 \\
\hline-1 & 0.0030 & 0.4413 & 0.1328 \\
\hline 0 & 0.0118 & $1.7671 *$ & 0.1446 \\
\hline 1 & 0.0164 & $2.4418 * *$ & 0.1610 \\
\hline 2 & 0.0103 & 1.5445 & 0.1713 \\
\hline 3 & 0.0044 & 0.6522 & 0.1757 \\
\hline 4 & -0.0127 & $-1.9019 *$ & 0.1629 \\
\hline 5 & 0.0077 & 1.1492 & 0.1706 \\
\hline 6 & 0.0003 & 0.0485 & 0.1710 \\
\hline 7 & 0.0017 & 0.2521 & 0.1727 \\
\hline 8 & 0.0056 & 0.8414 & 0.1783 \\
\hline 9 & -0.0036 & -0.5363 & 0.1747 \\
\hline 10 & 0.0028 & 0.4211 & 0.1775 \\
\hline 11 & 0.0011 & 0.1592 & 0.1786 \\
\hline 12 & -0.0018 & -0.2728 & 0.1768 \\
\hline 13 & 0.0052 & 0.7724 & 0.1819 \\
\hline 14 & -0.0073 & -1.0901 & 0.1746 \\
\hline 15 & -0.0142 & $-2.1272 * *$ & 0.1604 \\
\hline 20 & -0.0036 & -0.5371 & 0.1276 \\
\hline 30 & -0.0006 & -0.0815 & 0.0525 \\
\hline 40 & -0.0119 & $-1.7724 *$ & 0.0369 \\
\hline 50 & -0.0003 & -0.0501 & 0.0040 \\
\hline 60 & 0.0033 & 0.4958 & -0.0211 \\
\hline
\end{tabular}

\footnotetext{
$a_{\text {Average Excess Returns and CAXR's have been multiplied by } 10 \text { to }}$ facilitate reporting

* Significant at the 0.10 level

** Significant at the 0.05 level
}

returns may result in biased excess return measures. Sharpe and Cooper (1972) found that beta tends to be relatively stable over time. Reints and Vandenburg (1975) found that beta levels for stocks changing locations (OTC to an exchange) did not change significantly. In order to test for the stationarity of the beta estimate, the market model was re-estimated for each security using the following model:

$R(j t)=a(j)+b(j) R(m t)+b^{\prime}(j) D(j) R(m t)+e(j t)$

where $D(j)=0$ prior to inclusion on NMS for firm $j$

1 after inclusion on NMS for firm $j$

where $b(j)$ represents the market return coefficient prior to inclusion as measured over time from $t=-310$ to $t=-61$; and where $b^{\prime}(j)$ represents the market return coefficient after inclusion as measured over time frame $t=+61$ to $t=$ +310 . Given the number of trading days required to estimate $b(j)$ and $b^{\prime}(j)$, only stocks from January 1982 to June 1986 were used to test for beta stationarity.

Of the 1613 stocks that met the above requirements, 140 experienced a significant positive shift in beta while 124 
experienced a significant negative shift in beta. The 264 stocks represents $16.4 \%$ of the eligible sample. However, the number of increases in beta virtually equals the number of decreases. This result compares favorably with the results of Sanger and McConnell (1986). In addition, and similar to the results of Sanger and McConnell, the omission of stocks with significant shifts in beta did not appreciably change the results presented in Section IV A. Consequently, it appears that the return generating process is stationary and that excess returns based on that process are reliable measures.

\section{ii. Changes in NASD Requirements for Inclusion on NMS}

The excess returns results presented here may be influenced by the change in the requirements for inclusion on NMS as instituted on January 22, 1985. At that time, the changes promulgated by NASD made eligibility possible for many more OTC stocks. NASD determined that financial criteria (such as profitability of companies) were more important than trading activity in any particular stock. As one of the changes, the minimum bid price was lowered from the previous $\$ 5$ per share to $\$ 3$ per share. Consequently, many more lower priced issues became eligible for inclusion on the NMS in 1985.

In order to test for the impact of the new eligibility requirements, the sample was split into two time segments, 1982-84 $(\mathrm{N}=776)$ and 1985-87 $(\mathrm{N}=970)$. Tables 2 and 3 show the summary results for 1982-84 and 1985-87,

TABLE 2

Excess Returns for the 1982-84 Subperiod

\begin{tabular}{|c|c|c|c|}
\hline Event Day & $\underline{\text { Average Excess }}$ Returns $^{\text {a }}$ & t-statistic & $\mathrm{CAXR}^{\mathrm{a}}$ \\
\hline-60 & -0.0059 & -0.5219 & -0.0059 \\
\hline-50 & -0.0112 & -0.1025 & -0.0795 \\
\hline-40 & -0.0031 & -0.2759 & -0.1376 \\
\hline-30 & -0.0101 & -0.9036 & -0.2355 \\
\hline-20 & -0.0188 & $-1.6722 *$ & -0.3544 \\
\hline-15 & -0.0083 & -0.7383 & -0.4114 \\
\hline-14 & -0.0165 & -1.4656 & -0.4279 \\
\hline-13 & -0.0138 & -1.2278 & -0.4416 \\
\hline-12 & -0.0026 & -0.2283 & -0.4442 \\
\hline-11 & -0.0177 & -1.5745 & -0.4619 \\
\hline-10 & -0.0085 & -0.7545 & -0.4703 \\
\hline-9 & -0.0132 & -1.1774 & -0.4836 \\
\hline-8 & -0.0093 & -0.8315 & -0.4929 \\
\hline-7 & -0.0037 & -0.3308 & -0.4966 \\
\hline-6 & 0.0125 & 1.1135 & -0.4841 \\
\hline-5 & -0.0038 & -0.3349 & -0.4879 \\
\hline-4 & -0.0010 & -0.1515 & -0.4896 \\
\hline-3 & -0.0236 & $-2.0976 * *$ & -0.5131 \\
\hline-2 & -0.0145 & -1.2891 & -0.5276 \\
\hline-1 & -0.0065 & -0.5805 & -0.5341 \\
\hline 0 & 0.0098 & 0.8726 & -0.5243 \\
\hline 1 & 0.0110 & 0.9774 & -0.5133 \\
\hline 2 & -0.0079 & -0.7057 & -0.5213 \\
\hline 3 & -0.0197 & $-1.7567 *$ & -0.5410 \\
\hline 4 & -0.0101 & -0.8965 & -0.5511 \\
\hline 5 & -0.0089 & -0.7961 & -0.5600 \\
\hline 6 & -0.0056 & -0.4976 & -0.5656 \\
\hline 7 & -0.0028 & -0.2516 & -0.5684 \\
\hline 8 & -0.0026 & -0.2332 & -0.5710 \\
\hline 9 & -0.0221 & $-1.9675 * *$ & -0.5931 \\
\hline 10 & 0.0026 & 0.2344 & -0.590 \\
\hline 11 & -0.0040 & -0.3551 & -0.5945 \\
\hline 12 & -0.0194 & $-1.7241 *$ & -0.613 \\
\hline 13 & -0.0063 & -0.5568 & -0.620 \\
\hline 14 & -0.0160 & -1.4290 & -0.636 \\
\hline 15 & -0.0030 & -0.2641 & -0.639 \\
\hline 20 & -0.0083 & -0.7402 & -0.730 \\
\hline 30 & -0.0184 & -1.6386 & -0.878 \\
\hline 40 & -0.0026 & -0.2319 & -0.909 \\
\hline 50 & -0.0118 & -1.0536 & -1.050 \\
\hline 60 & -0.0017 & -0.1542 & -1.1128 \\
\hline
\end{tabular}

a Average Excess Returns and CAXR's have been multiplied by 10 to facilitate reporting

* Significant at the 0.10 level

** Significant at the 0.05 level 
TABLE 3

Excess Returns for the 1985-87 Subperiod

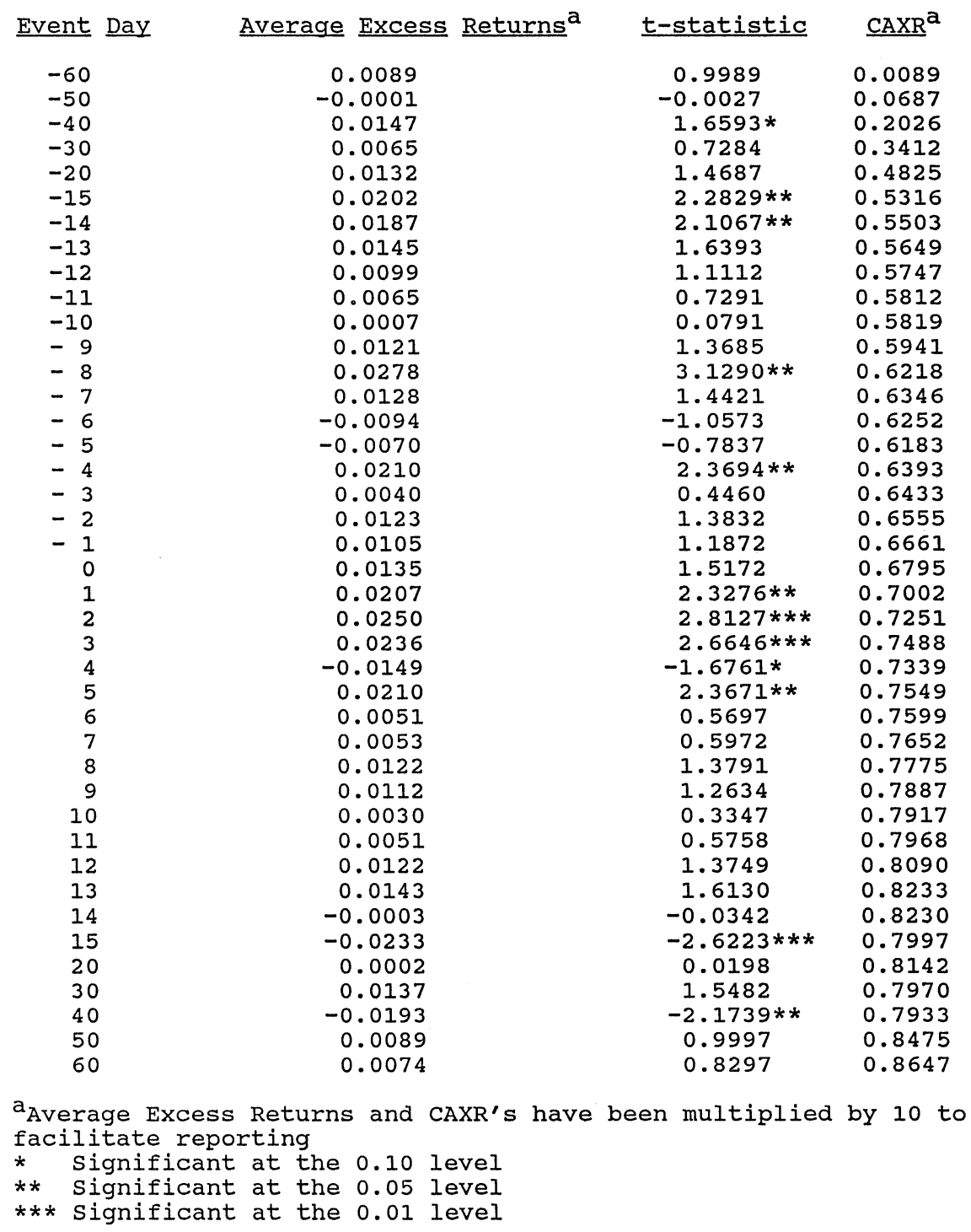

respectively. Positive but insignificant excess returns occur at days $t=0$ and $t=+1$ for the 1982-84 time frame; however, for the 1985-87 period, positive and highly significant excess returns $(p<0.05)$ occur for days $t=+1$ to $t=+3$. This difference in the significance of excess returns across the two subperiods may be due to one or a combination of the following factors. First, a seasoning process for the NMS may itself be present, producing uncertainty early on in its existence with regard to its role relative to organized exchanges. Second, the change in requirements in 1985 was instituted such that 200 stocks were added each and every month in 1985 to the NMS.(9) The clustering may produce a positive bias on the excess returns, assuming that addition to the NMS is a good thing (Brown and Warner (1985)). Third, as mentioned at the start of this section, the change in requirements in 1985 may produce a size effect.

First, concerning the seasoning process argument, the lack of knowledge on the part of investors with regard to the NMS may produce higher uncertainty and, therefore, higher risk early in its existence. In fact, the excess returns for 1982 additions $(\mathrm{N}=21)$ were negative and highly significant $(\mathrm{p}<0.05)$ for days $t=+1$ and +2 . Excess returns were positive but insignificant at day $t=0$ for 1983 additions, but positive and highly significant $(p<0.01)$ at day $t=+1$ for 1984 additions. Excess returns for each year's additions during the 1985-87 subperiod were positive for the event window (days $t=0$ to $t=+2$ ) and significantly so for 1985 and 1987 . Consequently, one could argue that there is present a seasoning process for stocks added to the NMS given the trend in the excess returns over time during 
the event window. In addition, the CAXRs for the two subperiods, as seen in Charts 2 and 3 , indicate that a seasoning process may be involved in the return process. The CAXR trend for the 1982-84 subperiod additions declines virtually throughout the $t=-60$ to $t=+60$ time frame, while that of the $1985-87$ subperiod additions is increasing throughout.

Second, the clustering affect would suggest that the

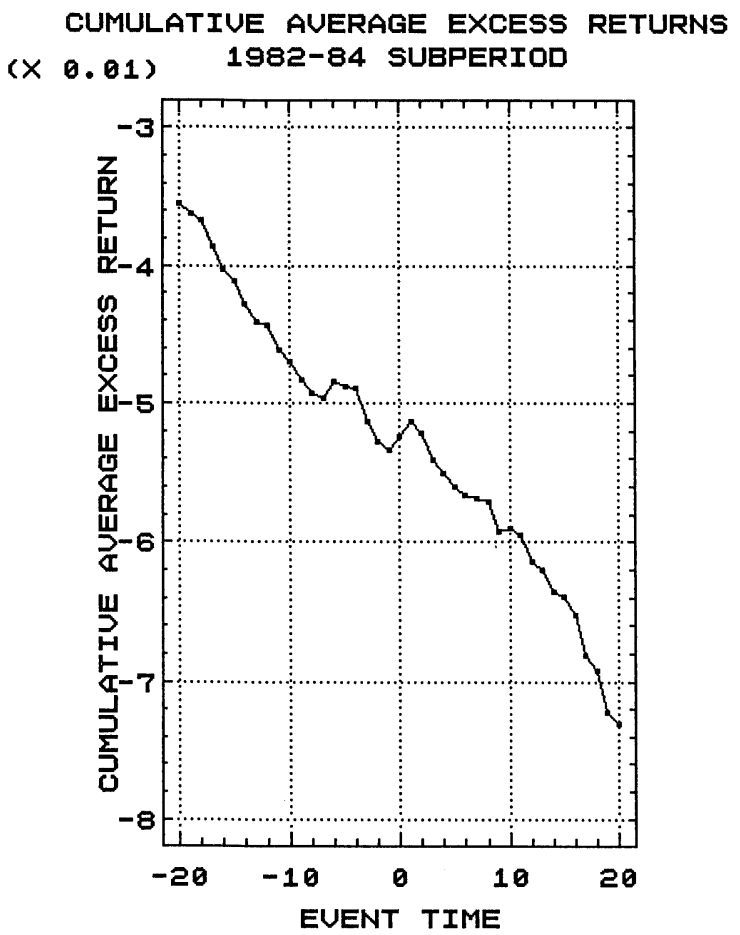

CUMULATIUE AUERAGE EXCESS RETURNS (x 0.01) 1985-87 SUBPERIOD

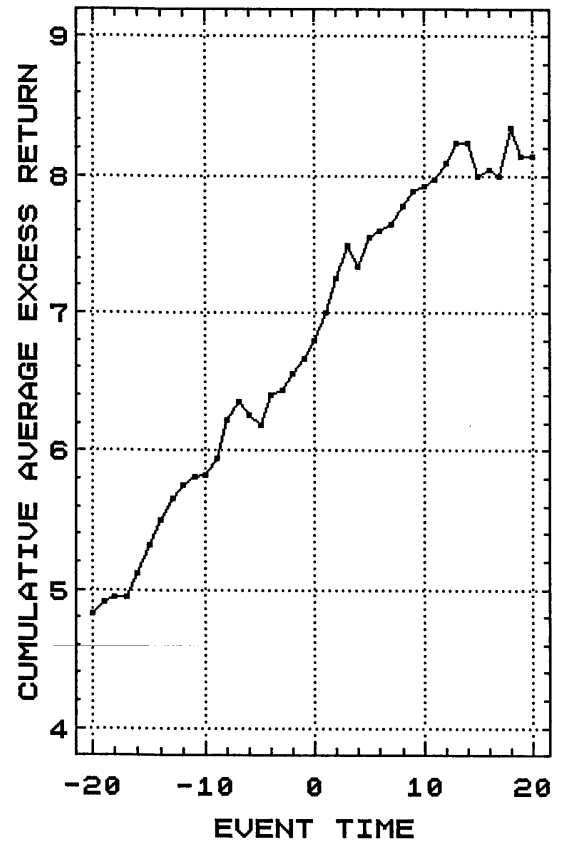

results for the 1985-87 period additions, in total, were due to the impact of adding 200 stocks each and every month during 1985. However, this would also suggest that excess returns for 1986 and 1987 additions would not be significant during the event window. As discussed above, the excess returns for 1987 additions were positive and significant. Therefore, although clustering may explain 1985, it does not explain the results for the entire 1985-87 period additions nor for 1983 and 1984 additions. Consequently, clustering is not considered to be an important factor for explaining the overall results.

\section{iii. Size Effect.}

Given the changes that were instituted in 1985 , the inclusion of stocks with bid prices as low as $\$ 3$ per share on the NMS suggests that a size effect may help to explain the overall results. In particular, one can hypothesize that inclusion on the NMS may be more important for companies with smaller market values than for ones with larger market values. The implication is that the stocks of smaller companies are less well known and, therefore, riskier than the stocks of larger companies. Inclusion on the NMS provides these companies with financial recognition. Thus, excess returns may be higher for small companies relative to large companies.

Stocks were placed into quintiles based on market value at the time of inclusion on NMS. Quintile 1 included the lowest market value stocks while Quintile 5 included the highest market value stocks. Stocks in Quintile 1 made up $3.6 \%, 8.0 \%, 29.3 \%, 32.1 \%$ and $32.8 \%$ of stocks added in years 1983, 1984, 1985, 1986 and 1987, respectively. Tables 4 and 5, and Charts 4 and 5, show the excess return results for Quintile 1 and Quintile 5, respectively, for 1982-87. The results indicate that for the largest stocks, inclusion on the NMS does not seem to provide any additional information to investors than what is already known. The excess returns for the Quintile 5 stocks were positive for day $t=0$, negative for days $t=+1$ to +3 , but insignificantly so for all days in the event window. The excess returns for the smallest stocks may be a very positive event based on the results in Table 4 as the excess returns, although negative and significant at day $t=0$, are positive for days $\mathbf{t}=+1$ to +3 and highly significant for days $\mathbf{t}=$ +2 and $t=+3$. The lag in the effect of the move to NMS (i.e., significant excess returns at days $t=+1$ to +3 for the small stocks) may be due to the time needed to gather information on these smaller stocks as well as the potential absence of liquidity for trading in these issues. Thus, trading may be spread over 2 or 3 days with a concomitant impact on excess returns. Also, given the frequency of small stocks within the sample by year, as mentioned above, the size effect may also explain the subperiod results since decidedly more small stocks appear in the 1985-87 subperiod than in the 1982-84 subperiod. 


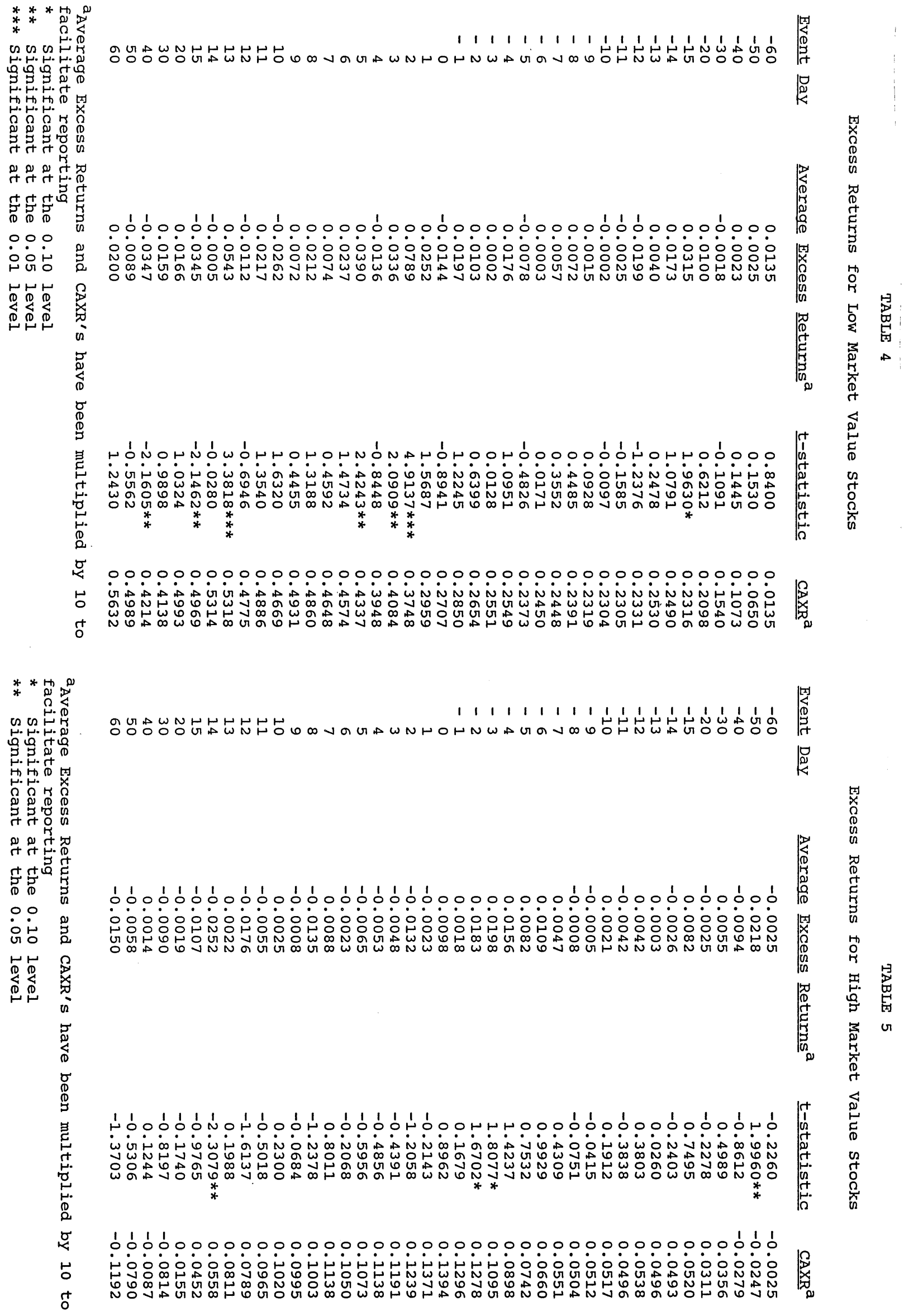




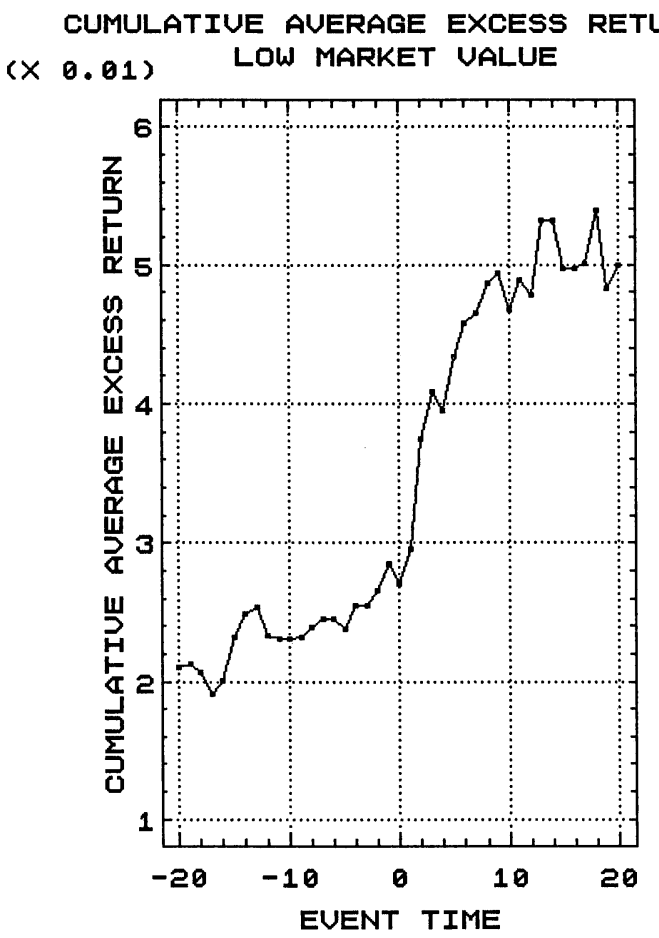

CUMULATIUE AUERAGE EXCESS RETURNS ( $\times 0.01)$ HIGH MARKET UALUE

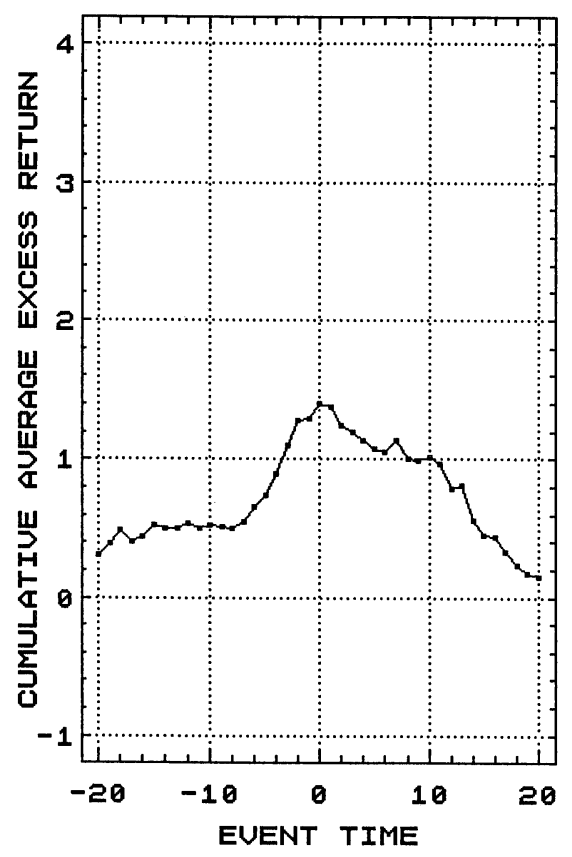

These results tend to support the results from the work of GP (Fall 1986, November 1986)] for stocks moving to an exchange from the OTC. That is, location of a stock on a national system of stocks is more beneficial for low market value stocks than for high market value stocks. The implication is that more information (and typically good information) is provided for a low market value stock moving to the NMS than for a high market value stock.

\section{Analysis of Volume}

The move from the OTC to the NMS may impact the trading activity in a particular stock.(10) In particular, it is anticipated that trading activity will increase for stocks that are added to the NMS. One reason for this anticipation is that information for stocks on the NMS is made available on a much more timely basis. Consequently, the stock could become more attractive to investors, both individual and institutional.

Trading activity is measured by turnover for a particular stock.(11) Daily turnover is defined by

$V(j, t)=\frac{\text { Shares Traded }(j, t)}{\text { Shares Outstanding }(j, t)}$

Shares traded and shares outstanding for stock $\mathrm{j}$ on day $t$ are taken from the CRSP OTC tape. The use of this measure of trading activity is potentially biased given the time frame for the study as overall market volume of trading, and therefore individual stock volume of trading, was increasing. Therefore, a relative turnover measure is used and is defined by

$V R(j, t)=\frac{V(j, t)}{V(m, t)}$

where $\operatorname{VR}(j, t)=$ relative turnover for stock $j$ on day $t$ and $V(m, t)=$ market turnover for day $t$.

Daily shares traded for the stocks that make up the OTC Composite Index was received from NASD as was the total number of shares outstanding at the end of every month from 1982-87. A constant growth rate was assumed to exist for shares outstanding from the end of one month to the end of the next. A daily geometric mean growth in shares outstanding was then used to estimate daily shares outstanding for the market. Daily turnover for the market was then calculated in the same way as for each individual stock.

In order to determine the impact of addition to the NMS on a stock's trading activity, a control period was used against which to compare the trading activity around the addition date. The control period was set as day $\mathrm{t}=$ -240 to $t=-180$ and was used to determine the "control" average daily relative turnover. Average daily relative turnover was also estimated for the period prior to the event (i.e., day $t=-60$ to $t=-1$ ) and for the period after the event (day $\mathrm{t}=+1$ to $\mathrm{t}=+60$ ). Since the control period begins with day $t=-240$, and since volume on a daily basis for stocks on NMS was not available prior to 1982 , trading activity is measured only for $1983-87$ ( $N=1725$ vs. 1746 for the entire time frame). A T-test was performed to determine if trading 
activity for the pre- and post-event time frames was significantly different from the control period.(12) The results in Table 6 indicate that, after accounting for the effects of general market trading activity, relative trading activity increases significantly from the control period to the pre-event period and from the control period to the post-event period. In addition, trading activity increases significantly from the pre-event to the post-event period. The results are similar if one splits the sample into pre- and post-January, 1985. The results are also similar (with the exception of the pre- vs. post-addition periods for the lowest market value stocks) for the lowest and the highest market value stocks over the entire time frame (1983-87). The results, in general, would tend to support the idea that the market for a stock added to the NMS becomes more liquid and, therefore, more valuable to investors.

\section{Summary and Conclusions}

The paper examines the information effects associated with the addition of stocks to the NMS. In particular, stock returns and trading activity around the event day are examined to determine if addition to the NMS is a "good" event. A good event is defined as positive excess returns and increased trading activity.

With regard to stock returns, the event of addition to the NMS appears to be a positive one. However, it appears to be more positive for low market value stocks relative to high market value stocks. This result supports the work of Grammatikos and Papaioannou (Fall 1986, November 1986). The results are not overly influenced by shifting parameter estimates used to estimate excess returns nor by the influence of clustering that occurred in 1985 with requirement changes for inclusion on the NMS. There also appears to be a seasoning process evident as the excess return pattern for the early years of the NMS differs from the more recent years. With regard to trading activity, the results indicate that trading in stocks added to the NMS is higher in the post-addition period relative to control and preaddition periods.

TABLE 6

Comparison of Average Relative Turnover

Control vs. Pre-event Control vs. Post-event Pre-event vs. Post-event

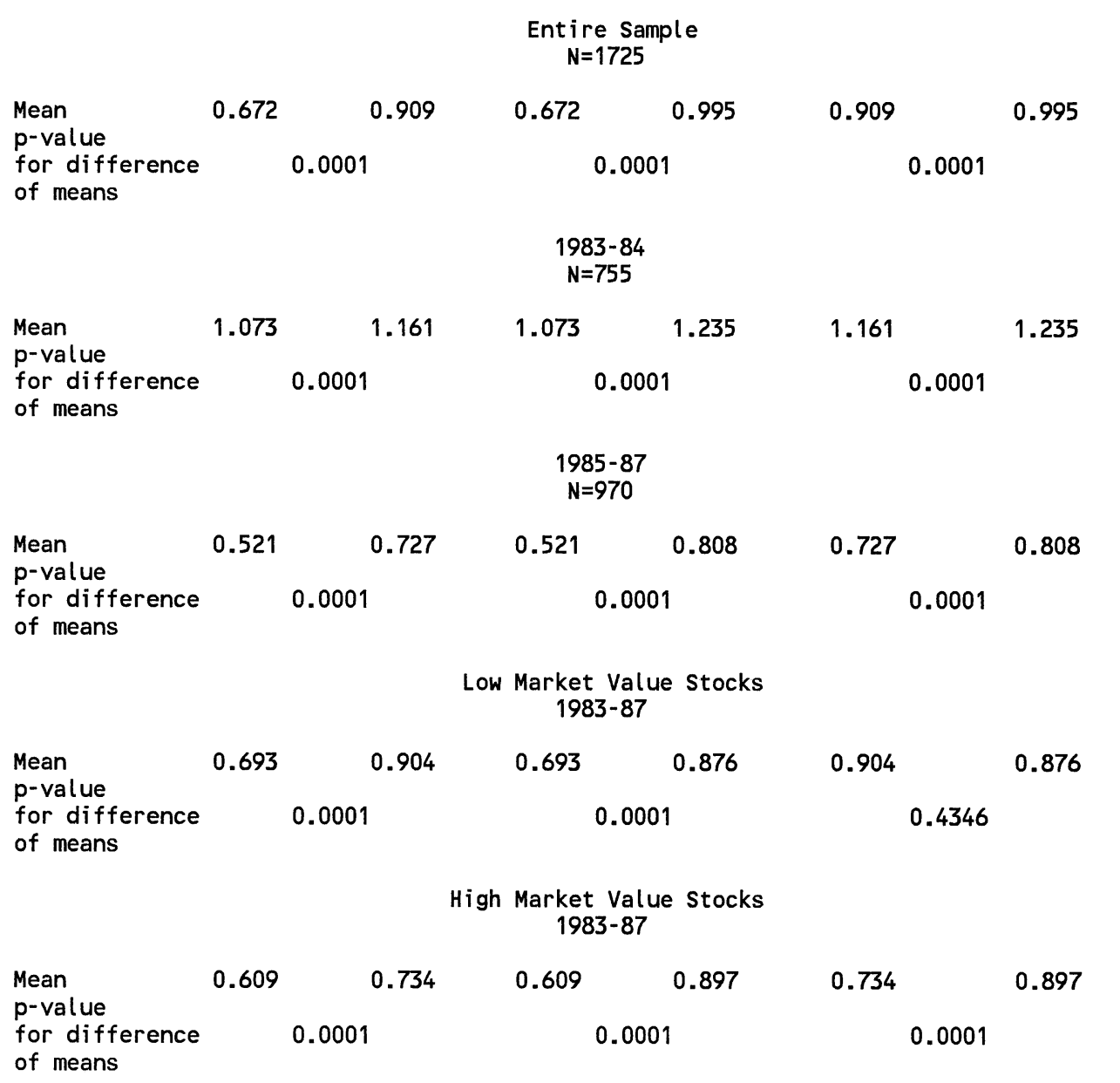


The proposed changes to the requirements for inclusion on the NMS are changes that make it more difficult for a stock to be added. In particular, the required size of the asset base is to be doubled as is capital and surplus. The number of publicly traded shares is to remain relatively close to current requirements and the minimum bid price is to remain at $\$ 3$. However, the number of market makers required to make a market for a particular stock is to be doubled from 2 to 4 . Based on these changes, as well as the results of this study, one can anticipate that the excess return pattern around the event day may more closely mirror the excess return patterns for higher market value stocks; and, therefore, addition may not provide any significant positive impact to the stock's returns. Trading activity, however, should still be anticipated to increase given addition to the NMS.

The authors wish to thank Gene Finn, William Wink, Kit Milholland and David Compton at NASD for their assistance.

\section{Appendix} by

Average portfolio excess returns (AXR) are determined

$\operatorname{AXR}(t)=\frac{\sum_{j=1}^{N} X R(j t)}{N}$

where $\mathrm{N}$ represents the number of stocks in the portfolio on day $t$. Cumulative average excess returns (CAXR) are determined over a time period from $t=a$ to $t=b$ and are measured by

$\operatorname{CAXR}(a b)=\sum_{t=a}^{b} \operatorname{AXR}(t)$

The t-statistic which tests for the significance of the AXR is defined by

t-stat $=\operatorname{AXR}(t) / S$

where $S$ is the standard deviation of the excess returns in the estimation period for the parameters of the model.

\section{Endnotes}

1 The paper deals only with the subject of inclusion on the NMS. Deletion from the NMS may contain information as well; however, for deletions, the size of the sample that met all criteria was only 24 in number. This size was deemed too small to derive results upon which to make general statements.
Work by Sanger and McConnell (1986) and Grammatikos and Papaioannou (Fall 1986) address this issue for stocks moving from the OTC to an exchange.

3 These requirements were changed most recently in 1989 , past the time period for this study. Another change in requirements occurred in January, 1985 and this issue is addressed in this study.

$4 \quad$ For the time period of this study, companies could be voluntarily placed on the NMS (based on the requirements for voluntary inclusion); or, if certain other requirements were met, companies could be automatically added (i.e., company management had no choice in the matter). This practice was changed with the most recent change in requirements (1989). Under the new policy, no stock is added on a mandatory basis. As compared to exchange listings, this is an extremely short period of time. At the very least, several weeks pass from the time of formal application to an exchange to the time of trading on the exchange (Sanger and McConnell, (1986)). Consequently, information leaks can substantially impact results for exchange listing studies.

The post-June 1987 period is omitted due to the influence of trading activity and stock price action in the middle of October, 1987 on parameter estimates. It is not felt that omission of the stocks added to NMS in the post-June 1987 period will negatively impact results of this study given the large sample size in the period that is under study.

7 This methodology is employed by others including, but not limited to, Sanger and McConnell (1986), Grammatikos and Papaioannou (Fall 1986), and Bhandari, et al. (1989).

The Dimson method was used to test for the effect of thin trading of smaller firms on the results. No difference was found between the results using the Dimson technique and those using OLS. Therefore, our conclusion is that the results are due to something other than the trading aspect of the small firm effect.

9 Although 200 stocks were added each and every month in 1985, not all stocks met the information requirements for being eligible to be in the sample. Of the stocks added to the NMS in 1985, sufficient information was available for 769 stocks.

10 Volume on NASDAQ-OTC issues is reported at the end of the trading day by individual dealers. Consequently, these numbers may be biased, up or down, by potential errors in dealer reporting. On the other hand, trading volume on NMS issues is reported on a per trade basis during the trading day. NMS volume numbers are there- 
fore considered to be more accurate.

11 Lakonishok and Smidt (1986) and Lakonishok and Lev (1987) have used turnover as a measure of trading activity.

12 The distribution of turnover for all three periods was determined to be normal based on the use of the Kolmogorov test statistic. Consequently, the use of a paired t-test is justified.

\section{References}

1 Bhandari, A., T. Grammatikos, A. Makhija, and G. Papaioannou. "Risk and Return on Newly Listed Stocks: The Post-Listing Experience," Journal of Financial Research, Vol. 12, No. 2, pp. 93-102, 1989.

2 Brown, Stephen and Jerold Warner. "Using Daily Stock Returns: the Case of Event Studies, " Journal of Financial Economics, Vol. 14, No. 1, pp. 3-31, 1985.

3 Dhaliwal, D. "Exchange Listing Effects on a Firm's Cost of Equity Capital," Journal of Business Research, Vol. 11, No. 2, pp. 139151, 1983.

4 Fabozzi, F. "Does Listing on the AMEX Increase the Value of Equity?" Financial Management, Vol. 10, No. 1, pp. 43-50, 1981.

5 Furst, R. "Does Listing Increase the Market Price of Common Stocks? Journal of Business, Vol. 43, No.2, pp. 174-180, 1979.

6 Grammatikos, T. and G. Papaioannou. "Market Reaction to NYSE Listings: Tests of the Marketability Gains Hypothesis, "Journal of Financial Research, Vol. 9, No. 3, pp. 215-227, Fall 1986.

7
"The Informational Value of Listing on the NYSE," Financial Review, Vol. 21, No. 4, pp. 485-499, November 1986.

Keim, Donald B. "The Daily Returns-Size Connection, " Journal of Portfolio Management, Vol. 13, no. 2, pp. 54-60, 1987.

Lakonishok, Josef and Seymour Smidt. "Volume for Winners and Losers: Taxation and Other Motives for Stock Trading, " Journal of Finance, Vol. 41, No. 4, pp. 951-974, 1986.

Lakonishok, Josef and Baruch Lev. "Stock Splits and Stock Dividends: Why, Who, and When," Journal of Finance, Vol. 42, No.4, pp. 913-932, 1987.

McConnell, J. J. and G. C. Sanger. "A Trading Strategy for New Listings on the NYSE," Financial Analysts Journal, Vol. 40, No.1, pp. 34-38, 1984. Common Stock Returns," Journal of Finance, Vol. 42, No.1, pp. 119-140, 1987.

Reints, W. W. and P. A. Vandenberg. "The
Impact of Changes in Trading Location on a Security's Systematic Risk," Journal of Financial and Quantitative Analysis, Vol. 10, No. 5, pp. 881-890, 1987.

14 Roll, Richard. "A Possible Explanation of The Small Firm Effect," Journal of Finance, Vol. 36, No. 4, pp. 879-888, 1981.

15 Sanger, G. C. and J. J. McConnell. "Stock Exchange Listings, Firm Value, and Security Market Efficiency: The Impact of NASDAQ," Journal of Financial and Quantitative Analysis, Vol. 21, No. 1, pp. 1-25, 1986.

16 Sharpe, W. F. and G. M. Cooper. "Risk-Return Classes of New York Stock Exchange Common Stocks, 1931-67," Financial Analysts Journal, Vol. 28, No. 2, pp. 46-54, 1972.

17 Van Horne, J. C. "New Listings and Their Price Behavior," Journal of Finance, Vol. 25, No.4, pp. 783-794, 1970.

18 Ying, L. W. Lewellen, G. Schlarbaum, and R. Lease. "Stock Exchange Listings and Securities Returns," Journal of Financial and Quantitative Analysis, Vol. 12, No. 3, pp. 425-432, 1977. 